\title{
Русский язык во французской средней школе: проблемы и перспективы изучения
}

Катрин Одан

DOI: 10.30547/mediaalmanah.6.2020.220229

(c) Одан Катрин академический инспектор региональный педагогический инспектор русского языка (г. Париж, Франция)
Французская система среднего образования является исключительной по уровню преподавания живых языков. Ученики могут выбрать из большого количества языков, занятия ведут квалифицированные преподаватели, и для нашей страны это - богатство.

Особенность преподавания живых языков в средней школе, в коллежах и лицеях, заключается, с одной стороны, в необходимости для всех школьников изучать два живых языка, а с другой - в большом разнообразии предлагаемых для изучения языков, которое можно назвать уникальным для Европы. Это иностранные языки (английский, испанский, немецкий, итальянский, китайский, португальский, арабский, русский, иврит, японский, голландский), а также региональные языки, хотя распределение их неравномерно. Как и другие живые языки, русский язык изучается в средней школе и, реже, в начальной.

С 2005 г. количество французских школьников, изучающих русский язык, постоянно снижалось, но в 2018-2019 гг. оно немного увеличилось и составило 12808 человек (см. табл.). Русский язык находится на восьмом месте по популярности после английского (в лицее) - 99,8\%, испанского - 73,5\%, немецкого - 20,6\%, итальянского - 7,6\%, китайского, португальского и арабского. Менее популярны, чем русский язык, иврит, 


\title{
L'enseignement du russe dans le secondaire en France : problèmes et perspectives
}

\author{
Catherine Hoden
}

Le système secondaire français est un système remarquable en ce qui concerne l'enseignement des langues vivantes puisqu'il offre aux élèves le choix entre de nombreuses langues, enseignées par des enseignants qualifiés, et c'est une richesse pour notre pays.

La spécificité de l'enseignement des langues vivantes dans le secondaire en France est d'une part l'obligation pour tous les élèves d'étudier 2 langues vivantes, et d'autre part une très grande diversité de l'offre, cas assez unique en Europe : les langues étrangères Anglais, espagnol, allemand, italien, chinois, portugais, arabe russe, hébreux, japonais, néerlandais...et les langues régionales sont présentes, certes inégalement, dans les collèges et les lycées. Le russe comme les autres langues vivantes est présent dans le $2^{\mathrm{d}}$ degré et dans une moindre mesure dans le 1 degré.

Après une érosion régulière depuis 2005 , les effectifs d'élèves français apprenant le russe en 2018/2019 étaient en très légère augmentation avec 12808 élèves. Le russe est la 8ème langue la plus enseignée après : l'anglais (au lycée) 99,8 \%, l'espagnol $73,5 \%$, puis loin derrière, l'allemand $20,6 \%$, l'italien 7,6\%, le chinois, le portugais et l'arabe et devant l'hébreux, le japonais et le néerlandais. Soit $0,2 \%$ des élèves étudient le russe dans le Secondaire (6ème $-\mathrm{T}$ ). (le portugais, l'arabe et le russe représentaient 0,5\% )

Évolution des effectifs d'élèves étudiant le russe dans le 2d degré 2005-2018

\begin{tabular}{|c|c|c|c|c|c|}
\hline Année & 2005 & 2011 & 2015 & 2017 & 2018 \\
\hline $\begin{array}{c}\text { Nbre d'élèves } \\
\text { Collège+lycée }\end{array}$ & 15153 & 14137 & 12331 & 12775 & 12808 \\
\hline
\end{tabular}

Si l'enseignement du russe est encore présent dans toutes les académies de la Métropole à l'exception de la Corse, la situation est disparate. Les " pôles » les plus dynamiques sont dans l'ordre:

Académie de Versailles, Académie de Paris, Académie de Bordeaux, Académie de Lyon, Académie de Montpellier, Académie de Rennes, Académie d'Aix-Marseille.

Dans les autres académies la situation est préoccupante. Il ne reste parfois plus que deux ou trois établissements qui proposent encore le russe même dans 
Таблица. Изменение количества учеников, изучающих русский язык в средней школе (коллеж и лицей, выборочно по годам)

\begin{tabular}{|c|c|c|c|c|c|}
\hline Год & $\mathbf{2 0 0 5}$ & $\mathbf{2 0 1 1}$ & $\mathbf{2 0 1 5}$ & $\mathbf{2 0 1 7}$ & $\mathbf{2 0 1 8}$ \\
\hline Кол-во учеников & 15153 & 14137 & 12331 & 12775 & 12808 \\
\hline
\end{tabular}

японский и голландский. Таким образом, в средней школе, от 6 класса коллежа до выпускного класса лицея русский язык изучают 0,2\% школьников (на португальский, арабский и русский вместе приходилось 0,5\% от общего числа учеников).

Хотя русский язык преподается во всех учебных округах метрополии Франции, за исключением Корсики, ситуация неоднородна. Список самых активных «полюсов» (учебных округов) в порядке убывания: Версаль, Париж, Бордо, Монпелье, Ренн, ЭксМарсель. В других учебных округах ситуация вызывает беспокойство. Иногда остается всего два илитри учебных заведения, в которых еще преподают русский язык, даже в тех регионах, где раньше русский язык был гораздо более распространен например, в учебных округах Гренобль или Лилль.

Средняя школа. Русский язык теоретически можно выбрать в качестве первого живого языка в шестом классе коллежа, однако его практически не выбирают в качестве первого иностранного языка (LVI/A), в отличие от английского. Русский язык можно изучать в рамках двуязычной секции английский/русский (таких секций 23), где оба языка преподают одновременно (шесть часов в неделю, количество часов на каждый из них определяет советник по воспитательной работе).

В качестве второго живого языка (LV2) LVB) русский язык можно выбрать с пятого класса коллежа (отметим, однако, что подавляющее большинство школьников изучают как второй иностранный язык испанский), а со второго класса лицея - в качестве третьего (LV3/LVC) (примерно 52\% школьников).
Начальная школа. В некоторых начальных школах в рамках так называемой «системы двух языков» осуществляются образовательные программы, благодаря которым школьники могут начать изучение русского языка на ранних этапах. Иногда он выступает в качестве основного языка, чаще - неосновного, в сочетании с английским. Такая система действует, например, в образовательных округах Ницца, Бордо, Версаль, Кретей и Амьен. Кроме того, иногда в рамках связующих программ «школа/коллеж» преподаватели коллежей и учителя школ совместно проводят вводные занятия или проекты. К несчастью, для введения этой программы возникает препятствие - нехватка учителей, которые могли бы вести этот курс (проблема учета и распределения часов, отработанных преподавателями средней школы).

Международные отделения (SI). С тех пор как в 2009 г. министрами Франции и России была подписана декларация о намерениях, касающаяся создания международных отделений с русским языком, было создано десять таких секций:

- четыре секции в лицеях: лицей Понтонье в Страсбурге (2010 г.), международный лицей Вальбонн (образовательный округ Ницца, 2009 г.), международный лицей Сен-Жермен ан Ле (образовательный округ Версаль, 2010 г.), лицей Камий Жюлиан в Бордо (2011 г.);

- три секции в коллежах: коллеж Вернье в Ницце (2013 г.); коллеж при лицее имени Александра Дюма в Москве (2014 г.), коллеж Марселя Роби в Сен-Жермен ан Ле (2017 г.);

- три секции в начальной школе: секция в начальной школе при лицее имени Александра Дюма в Москве (2015 г.), секция 
certaines régions où l'enseignement du russe était autrefois très développé comme l'Académie de Grenoble ou de Lille.

\section{Statut du russe}

- Le russe peut être choisi en 6ème non pas en LVI/A (Il a quasiment disparu comme LVl au profit de l'anglais) mais dans le cadre des sections bilangue anglais/russe dans lesquelles les deux langues sont enseignées en même temps à raison de 6 heures hebdomadaires (c'est au CE que revient la décision d'attribuer un nombre d'heures à chaque langue). Elles étaient au nombre de 23 sur le territoire.

- En LV2/LVB à partir de la 5ème ou en LV3/LVC à partir de la 2de.

Remarque : environ $52 \%$ des élèves qui étudient le russe au lycée le choisissent en 3ème langue, nommée LVC désormais. (pour rappel, l'écrasante majorité des élèves étudient l'anglais en LVA et l'espagnol en LVB).

- Le premier degré

Un enseignement est mis en place dans certaines écoles primaires dans le cadre du dispositif dit " dispositif bilangue ». Les élèves peuvent ainsi y bénéficier d'un enseignement précoce en russe parfois comme langue principale, le plus souvent non principale en sus de l'anglais. Ceci existe dans les Académies de Nice, de Bordeaux, de Versailles, de Créteil ou d'Amiens par exemple. De plus, des initiations ou des projets sont parfois menés conjointement par les professeurs en poste au collège et des professeurs des écoles dans le cadre de la liaison école/collège. Malheureusement la mise en place de cet enseignement se heurte au manque de professeurs susceptibles d'intervenir ( $p b$ de comptabilisation et de prise en charge des heures effectuées à l'école par des enseignants du second degré).

- Les sections internationales $\mathrm{SI}$

Depuis qu'une déclaration d'intention a été signée par les ministres français et russe en 2009 sur la création de sections internationales de russe, 10 sections internationales (SI) de russe se sont développées : c'est un dispositif à la marge du système puisqu'elles scolarisent des enfants issus de familles russophones ou enfants d'expatriés.

Le public y est très varié selon les implantations. Ces Sections peuvent être pour des enfants russophones de tous milieux et origines de véritables passerelles vers le système français et en leur permettant de se familiariser avec un système qu'ils ne connaissent pas et de mieux s'y intégrer pour ensuite poursuivre leurs études dans de bonnes conditions.

- 4 sections en lycée : lycée des Pontonniers à Strasbourg (2010), lycée international de Valbonne (académie de Nice, 2009), lycée international de Saint-Germain en Laye (académie de Versailles, 2010), lycée Camille Jullian à Bordeaux (2011).

- 3 sections en collège : collège Vernier à Nice (2013) ; collège de la Cité scolaire Alexandre Dumas à Moscou (2014) ; collège Marcel Roby de SaintGermain en Laye (2017).

- 3 sections dans le premier degré : Une section en école élémentaire à la cité scolaire Alexandre Dumas à Moscou (2015), une à l'école Littré à Paris (2018) et une à l'école Ronchèse à Nice (2013).

Rentrée 2018 : en France, 226 élèves étaient scolarisés dans les 6 SI du second degré. 
в школе Литтре в Париже (2018 г.) и секция в школе Роншез в Ницце (2013 г.).

В 2018/2019 учебном году во Франции в шести международных отделениях в средней школе обучалось 226 учеников. Это направление является дополнением к общей системе, поскольку с его помощью получают образование дети из русскоязычных семей или дети мигрантов.

Контингент учащихся международных отделений очень сильно зависит от региона. Для русскоязычных детей из разных социальных слоев и стран эти отделения могут быть настоящим «мостом» во французскую систему, что способствует их интеграции и продолжению учебы в хороших условиях.

В 2018 г. во Франции было 223 учителя русского языка. Почти половина из них (101) работали по контракту, не в штате. В течение нескольких лет (до 2010 г.) конкурс на новые должности почти не открывался, что, естественно, привело к уменьшению и даже отмене количества часов. В 2018 г. было открыто шесть вакансий (три по внутреннему свидетельству о специальной профессиональной подготовке работников среднего образования (Capes) и три по внешнему конкурсному экзамену (Aggregation). В 2019 г. это количество составило восемь (пять по Capes и три по Aggregation).

Стоит отметить, что большинство преподавателей русского языка ведет активную деятельность. Они, нередко в одиночку, организуют масштабные программы обмена с российскими школами, ведут просветительскую деятельность среди школьников и учеников коллежей, вместе с учениками участвуют в проектах, часто не имея никакой поддержки. Они нуждаются в помощи специалиста, который мог бы на время взять нагрузку на себя, тем более что условия их работы становятся хуже (назначения в три разных образовательных учреждения нередки).

Наконец, каждый год в учреждения среднего образования Франции приезжают по направлению из России 45 ассистентов, труд которых оплачивает французская сторона. Присутствие молодых россиян в учебных заведениях Франции представляет интерес во многих аспектах.

Всеобъемлющая реформа лицея и системы бакалавриата, которая проводится сейчас во Франции, заставляет нас пересмотреть место, которое отводится преподаванию живых языков (кроме английского) в нашей системе. Но соответствуют ли наши возможности нашим желаниям? Действительно, складывается парадоксальная ситуация.

С одной стороны, намерения, о которых заявляют в Министерстве образования, ясны. На самом высшем уровне продолжают говорить, что многоязычие важно и нужно поддерживать и развивать языковое разнообразие в коллежах и лицеях, а также в начальной школе. Также утверждается важность изучения таких языков, как арабский, китайский и русский, «великих языков цивилизации», как их назвал министр, и снова придать им «престижность» (стоит отметить, что эти три языка находятся символически на разных уровнях). То же относится к принципу территориального равенства «для создания большей свободы, большего выбора, углубления знаний, открытости, цельности» (о нем постоянно напоминают). На высшем уровне понимают, что Франции нужно все больше русскоговорящих специалистов, получивших образование в нашей системе, чтобы обеспечивать и развивать политические, геополитические, экономические, торговые, культурные и научные связи между Францией и Россией на высоком уровне, а также для распространения культурного влияния Франции в России и на постсоветском пространстве.

С другой стороны, существует реальное положение дел на местах. В вопросах открытия/закрытия учебных программ и в коллежах, и в лицеях чаще всего решающей является финансовая составляющая. 
Les enseignants de russe étaient au nombre de 223 en 2018 dont presque la moitié (101) de contractuels, non titulaires. Pendant plusieurs années les postes aux concours de l'enseignement ont été plus ou moins gelés. Engrenage : pas de professeurs= fermeture ou réduction des heures. Une régularité dans l'ouverture de ces postes est rétablie depuis 2010.6 postes ont été proposés en 2018 ( 3 au CAPES interne et 3 à l'agrégation) et 8 en 2019 ( 5 au Capes externe et 3 à l'agrégation).

Il faut souligner l'engagement de la majorité des professeurs de russe qui organisent seuls souvent de très nombreux échanges chaque année avec des écoles de Russie, mènent des actions de sensibilisation auprès des écoliers et des collégiens, prennent part avec leurs élèves à des projets sans être toujours soutenus, loin s'en faut. Ils auraient besoin de relais. D'autant que leurs conditions de travail se dégradent (affectation sur 3 établissements n'est pas rare).

Enfin, 45 assistants russes, envoyés par la Russie et rémunérés par la France, sont accueillis chaque année en France par les établissements d'enseignement secondaire. Cette présence de jeunes russes dans les établissements est intéressant à plusieurs titres.

\section{Commentaires}

La réforme de fond du lycée et du baccalauréat qui est en train d'être appliquée oblige à réinterroger la place que doit occuper l'enseignement des langues vivantes autres que l'anglais dans notre système.

Nous donnons nous les moyens de nos ambitions?

$\Rightarrow$ Une situation effectivement paradoxale

1. Les intentions affichées d'une part :

- Les intentions affichées dans les propos du ministre de l'Éducation sont claires. On continue d'affirmer, au plus haut niveau, que le plurilinguisme est important, qu'il faut maintenir voire développer la diversité linguistique dans les collèges et les lycées et même dans le premier degré, et on réaffirme l'importance de l'étude de langues comme l'arabe, le chinois et le russe qualifiées de " grandes langues de civilisation " par le ministre et leur redonner du " prestige ». (Noter que ces trois langues ne sont pas sur le même plan, symboliquement parlant)

- De même le principe de l'équité territoriale " pour plus de liberté, de choix, d'approfondissement, d'ouverture, de cohérence » est constamment rappelé.

- On a conscience au plus haut niveau que la France a un besoin, croissant, de russisants formés par notre système éducatif pour garantir et développer entre la France et la Russie des relations politiques et géopolitiques, économiques, commerciales, culturelles et scientifiques de grande qualité, et pour assurer le rayonnement de la France en Russie et dans une grande partie de l'ex URSS.

2. La réalité d'autre part sur le terrain

- La logique financière prime le plus souvent dans les ouverture et fermeture, en collège comme en lycée, sans qu'une vue d'ensemble au niveau national permette véritablement de veiller de façon efficace à une répartition équilibrée ni à la pérennité des enseignements dits " rares ". L'administration locale, des chefs d'établissement au niveau des bassins aux recteurs au niveau académique, ne se rendent souvent pas compte de ce que peut engendrer une fermeture.

- La réforme et la nouvelle architecture du lycée et du baccalauréat induit : 
При этом нет возможности оценить всю обстановку на национальном уровне, следить за равным распределением и преемственностью "редких» образовательных программ. Местная администрация, от главы образовательных учреждений (на уровне района) до ректоров (на уровне учебного округа), не осознает, что может привести к закрытию программы.

Реформа и новая архитектура лицея и системы бакалавриата вызывает уже заметное снижение количества учеников, которые решают изучать третий живой язык (например, в 2019/2020 учебном году в учебном округе Версаль третий язык во втором классе лицея выбрали 15,8\% учеников, а во втором и первом классах лицея - 43\%). Соответственно, русский язык тоже изучают меньше (напомним, что 52\% учеников изучают его именно в качестве третьего). Сейчас на выпускном экзамене за третий язык не дают дополнительных баллов (учитывается только средний балл, что приносит ученику менее $0,1 \%$ от общей оценки). Кроме того, предлагаемое расписание отпугивает даже самых мотивированных учеников. Объединение в группы учащихся разных уровней, часто с нарушением педагогических принципов, создает сложности для преподавателя. Первая обратная связь от коллег вызывает обеспокоенность (резкое или запланированное закрытие программ, снижение количества часов, слияние групп и т.д.).

Как следствие - целые регионы становятся «пустынями русского языка» (учебные округа Амьен, Кан, Клермон-Ферран, Лимож, Реймс, Страсбург, Тулуза и др.), а запросы семей руководство учебного округа иногда перенаправляет в частные учреждения, в то время как у нас есть штат компетентных преподавателей, которым часто не хватает работы. Приведем несколько конкретных примеров в двух разных учебных округах:

- Ницца, Лицей Парк Империаль: было принято решение закрыть программы третьего языка для вторых и первых классов лицея без возможности продолжения. При этом в учебном округе Ницца больше нет отделений русского языка как первого или второго, несмотря на большое количество русскоговорящих в регионе и наличие выгоды (как культурной, так и экономической) в преподавании русского языка в этом регионе.

- Лион: закрытие программы русского языка как третьего в лицее Сент-Юст, несмотря на то что там обучалось больше всего учеников в учебном округе. Также закрылось отделение третьего языка в лицее Сент-Экзюпери. В Лионе осталось только два центра с изучением русского языка как третьего: лицей Ампер и лицей дю Парк. Во всем учебном округе русский как первый и второй язык преподают только в одном учреждении (коллеж и лицей Ампер).

Тем не менее возможности для улучшения ситуации есть. Предложения в этом направлении либо разрабатываются, либо уже применяются. Возможно, есть причины сохранять оптимизм. Для этого необходимо внутри образовательной системы вести активную политику:

- Создать и распространить гибкую систему обучения, разрешив и, может, даже систематизировав возможности особого подхода для так называемых «нераспространенных языков», чтобы дать всем одинаковые возможности по изучению русского языка. Это уже успешно практикуется (например, в Монпелье и Реймсе, где в 2019 г. русский язык выбрали 30 человек, как в шестом классе коллежа, так и во втором классе лицея).

- Обязательно предоставить возможность изучения русского языка, а также других редких или «нераспространенных» языков во всех учебных округах в качестве второго иностранного (а может, даже и первого) и третьего, а именно: открыть двуязычные секции и отделения второго языка, что позволит исправить ситуацию со снижением числа учеников на программах третьего 
Une diminution, qui peut déjà être déjà observée (cf. dans l'Académie de Versailles en LVC $-15.8 \%$ des inscrits en 2de à la rentrée 2019et -43\% en 2de et lère) du nombre d'élèves choisissant d'étudier une langue vivante $C$, et donc le russe, nous le rappelons 52\% des apprenants le sont en LVC ex LV3. En effet, plus aucune bonification n'est prévue au bac pour les élèves de LVC (seule sera prise en compte la moyenne du bulletin, ce qui rapportera à l'élève que moins de $0,1 \%$ de la note globale). De plus, les horaires proposés découragent les élèves les plus motivés. Les regroupements de niveaux souvent anti pédagogiques sont très difficiles à gérer pour les professeurs. Les premiers retours des collègues sont inquiétants (fermetures sèches ou programmées, réduction des horaires, fusion des groupes...)

- Conséquence : des régions entières deviennent des " déserts de russe " (académies d'Amiens, Caen, Clermont-Ferrand, Limoges, Reims, Strasbourg, Toulouse... et les demandes des familles sont parfois renvoyées, hélas même par les services rectoraux, vers des organismes privés, alors que nous avons un corps d'enseignants titulaires compétents, souvent sous-employés.

- Quelques exemples concrets dans 2 académies différentes :

Nice, Lycée du Parc impérial : décision de fermeture sèche de la LV3 sans continuité pour les 2 ndes et lères. Or, il n'existe plus de sections russes LV1 et LV2 (LVA/LVB) dans l'académie de Nice, malgré une forte présence de la communauté russophone et un intérêt, culturel comme économique, à l'enseignement du russe dans cette région.

Lyon : fermeture sèche de la LVC russe au Lycée Saint-Just, celui qui, pourtant, accueillait les plus gros effectifs de l'académie ; fermeture de la LVC également au Lycée Saint-Exupéry.

Il ne reste que 2 pôles LVC à Lyon : le lycée Ampère et le lycée du Parc.

Dans toute l'académie de Lyon, la LVA et la LVB ne sont enseignées que sur un seul pôle (collège et lycée Ampère).

$\Rightarrow$ Possibilités d'amélioration : elles existent pourtant : des propositions pour améliorer la situation sont soit à l'étude soit déjà en application. Il y a peut-être des raisons d'être optimistes.

- à l'intérieur du système éducatif, il s'agit de mener une politique volontariste.

1. généraliser l'assouplissement de la carte scolaire en autorisant voire systématisant les possibilités de dérogations pour les langues dites « à faible diffusion » afin de donner à tous la même chance d'étudier le russe ; cela se fait déjà, avec succès (par exemple à Montpellier ou Reims, où l'on trouve, cette rentrée, des effectifs de 30, aussi bien en 6ème qu'en 2nde)

2. instaurer l'obligation qu'un enseignement du russe, comme d'autres langues dites rares ou " à faible diffusion ", soit systématiquement proposé dans toutes les académies comme LVB (voire LVA) et LVC : favoriser les ouvertures en bilangue ou LVB permettant de pallier à la baisse des effectifs qui se dessine en LVC si rien n'est fait pour les soutenir.

3. consolider le statut des enseignements optionnels (dont la LVC) en permettant d'en choisir plusieurs, en augmentant leur apport à la note finale du baccalauréat.

4. offrir aux élèves ayant commencé le russe au collège (LVA, LVB) la possibilité d'étudier le russe comme langue de spécialité au même titre que l'anglais, l'espagnol, l'allemand, l'italien et les langues régionales, seules langues proposées à ce jour ; (éventuellement sous la forme d'une spécialité « langues » qui regrouperait 2 LV). 
языка, если ничего не будет сделано для их поддержки.

- Закрепить статус дополнительных образовательных программ (и в частности третьего иностранного языка), дать возможность выбрать несколько из них, увеличив степень их влияния на итоговую оценку на выпускном экзамене.

- Дать ученикам, которые начали изучать русский язык в коллеже (как первый или второй язык), возможность изучать русский как язык специальности (возможно, в виде специальности «языки», объединяющей два иностранных языка). Сейчас такой вариант можно выбрать для английского, испанского, немецкого, итальянского и региональных языков.

- Распространять достоверную информацию о разных языках, чтобы бороться с предрассудками о русском языке, который считается «языком элиты» во всех учреждениях.

- Благодаря более тесному сотрудничеству между Францией и Россией облегчить проведение обменов между французскими и русскими учебными заведениями: в частности, создать возможность для бесплатного получения визы для групп, учеников и учителей по упрощенной процедуре (сейчас существуют значительные сложности).

- Вновь предоставить возможность французским студентам работать ассистентами в России.

И в заключение хотелось бы обозначить позитивные тенденции.

Во-первых, несколько возрастает количество изучающих язык на курсах подготовки в высшие школы (на вступительных экзаменах ученики, изучающие русский язык, достигают особенно выдающихся результатов, и многие высшие школы, главным образом в сфере бизнеса, очень ценят русскоязычных абитуриентов). В системе высшего образования интерес к изучению русского языка не снижается и даже немного возрастает - в частности, среди неспециалистов и начинающих. Но условия приема студентов, по разным причинам не всегда оптимальны (нехватка часов на преподавание языка, невозможность открыть новые группы). Развитие преподавания русского языка в системе среднего образования также позволит увеличить количество специалистов, работающих в сфере высшего образования, открытьдля них вакансии (конкурсные места для специалистов).

Во-вторых, увеличивается, пусть и незначительно, количество конкурсных вакансий - в 2020 г. пять мест по внутреннему свидетельству о специальной профессиональной подготовке работников среднего образования (Capes) и четыре места по внешнему конкурсному экзаменy (Aggregation).

B-третьих, развивается сотрудничество: 2021 г. станет перекрестным годом регионального сотрудничества России и Франции. Подписано соглашение о партнерстве между Греноблем и Иркутской областью. Недавно состоялись контакты на уровне министров: 12 ноября в Париж прибыл первый заместитель министра просвещения РФП.С. Зенькович, а министр образования Франции Жан-Мишель Бланкер получил приглашение приехать в 2020 г. в Москву для подписания соглашений в сфере изучения языков и образования, что позволяет надеяться на светлое будущее.

В этом году в рамках «Трианонского диалога» для школ проводится литературный конкурс «Дорогое завтра!», посвященный интеллекту будущего. В Тулузе - фестиваль «Франко-российские музыкальные встречи», руководитель и дирижер - россиянин Туган Сохиев. По его просьбе в фестивале будут участвовать школьники, изучающие русский язык. В следующем году - программа «Трианон в школе» (в стадии разработки). Продолжение следует... 
5. dispenser une véritable information sur les différentes langues pour lutter contre les idées toutes faites sur la langue russe, langue " élitiste " au sein de toutes les instances.

6. Grâce à une coopération accrue entre la France et la Russie

- faciliter les échanges scolaires entre établissements français et russes et notamment permettre l'obtention des visas gratuits pour les groupes scolaires, élèves et professeurs, avec une procédure allégée. (de grosses difficultés existent actuellement).

7. Réinstaurer la possibilité pour des étudiants français de travailler comme assistants en Russie.

Pour terminer sur une note positive :

1. Post-bac

- des effectifs en CPGE (Classes préparatoires aux grandes écoles) sont en légère augmentation (les résultats aux concours des russisants sont particulièrement brillants et nombre de grandes écoles, essentiellement de commerce, sont très preneuses de candidats russisants).

- Dans l'enseignement supérieur l'intérêt pour l'apprentissage du russe ne se dément pas et augmenterait même très légèrement notamment parmi les non spécialistes et les débutants. Mais les conditions d'accueil des étudiants, pour différentes raisons, ne sont pas toujours optimales (manque d'heures dédiées à son enseignement, impossibilité d'ouvrir des groupes supplémentaires). Développer l'enseignement du russe dans le secondaire permettra aussi d'augmenter les effectifs dans le supérieur en leur offrant des débouchés (postes au concours pour les spécialistes)

2. Ressources humaines : Légère augmentation des postes mis au concours en 2020 : Capes interne 5 postes et agrégation externe 4 postes.

3. Coopération et accords

- 2021 sera l'année franco-russe de la coopération régionale. Grenoble a signé un partenariat avec région d'Irkoutsk.

- Les récents contacts à très haut niveau ont eu lieu : le Premier Vice-Ministre Zenkovitch était à Paris le 12 novembre, et le ministre français de l'éducation est invité pour signer des accords linguistiques et éducatifs courant 2020 ce qui laisse peut-être augurer d'un avenir meilleur.

-Les actions du « Dialogue de Trianon » en direction des scolaires :

Cette année, le concours d'écriture sur les intelligences du futur « Cher demain ». L'année prochain, le programme "Trianon à l'école » (en cours de conception).

À Toulouse, le festival "Les musicales franco-russes ", dirigées par le chef russe Tugan Sokhiev, associe, à sa demande, les scolaires russisants. 